Original Artide

\title{
Food Insecurity is Related to Women's Mental and Physical Health in Babolsar, Iran
}

AmirHossein Ramezani Ahmadi ${ }^{1}$, Ramin Heshmat ${ }^{2}$, AbouAli Vedadhir ${ }^{3}$, Seyyed Reza Sobhani ${ }^{4}$, Samira Ahmadi ${ }^{5}$, Hamed Pouraram ${ }^{* 6}$

1- PhD student, Student Research Committee, Ahvaz Jundishapur University of Medical Sciences, Ahvaz, Iran.

2- Assistant Prof, Endocrine and Metabolism Research Center, Tehran University of Medical Sciences, Tehran, Iran

3- Assistant Prof, Department of Demography and Population Studies, Faculty of Social Sciences, University of Tehran, Tehran, Iran.

4- PhD student, Students' Research Committee, Faculty of Nutrition Sciences \& Food Technology, Shahid Beheshti University of Medical Sciences,

Tehran, Iran.

5- MSc student, Department of Health and Food Safety, Qazvin University of Medical Sciences, Iran.

6- Assistant Prof, Department of Community Nutrition, School of Nutritional Sciences and Dietetics, Tehran University of Medical Sciences (TUMS), Tehran, Iran.

\section{A B S T R A C T}

Background and Objectives: Food insecurity has some adverse effects on health. Studies show that, there is a significant relationship between poor mental and physical health and food insecurity among low-income households. The purpose of this study is to investigate the relationship between household food insecurity and physical and mental health in Iranian women with high school age children.

Materials and Methods: This cross-sectional study was conducted on 289 women with high school aged children in Babolsar, Iranin spring 2015. General Information Questionnaire, 18-item USDA household food security questionnaires and health survey (SF-12) was completed by face-to-face interviews with the participants. The mental and physical health of the participants were compared based on food secure and food insecure group.

Results: Food insecurity was significantly related to age of the participants, living area (urban/rural), husbands job and education of women studied $(\mathrm{p}<0.05)$. Also, food insecurity was significantly associated with poor physical health score $(\beta=-1.079, \mathrm{P}<0.001)$ and mental health $(\beta=-0.728, \mathrm{P}<0.001)$. This relationship remained significant after adjusting for age, family size, residential area, education, job, husband's job and education.

Conclusions: Therefore, household food insecurity is an independent risk factor for poor mental and physical health in women with high school aged children. The findings of this research provide insights for the future as the crucial role of woman and their significant impact on food security and the health status of the household can be used to develop targeted interventions aimed at women with children.

Keywords: Food insecurity, Mental health, Physical health, Woman

\section{Introduction}

Access to food is one of the essential needs of human. "Food security means that all people at all times have physical, social and economic access to adequate, safe and nutritious food for the body requirements and preferences for an active and healthy life" (1). Food insecurity ranges between fear of inadequate access to food to severe hunger $(2,3)$.

According to previous studies, the prevalence of food insecurity was reported from $5.7 \%$ to $73 \%$ in developing countries (4-6). This ratio was $10 \%$ to $11.2 \%$ in developed countries $(7,8)$. Economic status, 
ethnicity, age and education level of household heads, unemployment, lack of steady job or savings, increase in family size, cost of rent and loss of food aid are related to food insecurity (9-12). Families with a low socio-economic level are experiencing a shortage of food more than others and are not able to buy enough healthy and nutritious food (13-15). Inability to provide enough food can cause psychological stress which can have adverse effect on mental health.

Studies have indicated a relationship between food insecurity and inadequate intake of micronutrients, obesity, depression, and decreased mental health in women with low-income households. This can cause impaired development of mental health as well as psychological and behavioral dysfunction in children and adults (16). Part of the association between food insecurity and chronic diseases is due to more intake of cheap foods with high energy density that alleviates hunger, but rather poor micronutrients status $(17,18)$.

Studies have shown a dramatic increase of mentalhealth problems in the communities facing food insecurity (19). Mental problems can prevent the ability to concentrate and reduce the incentive in people (20). Studies show that food insecurity can reduce mental health and increase the risks related to growth and development (21). Mothers are very important and influential members of the family, particularly for studying the consequences of food insecurity (22). They have the desire to protect other family members, especially children, so put themselves at greater risk of food insecurity. As a result, food insecurity may have the most adverse impact on physical and mental health of women (23). Food insecurity can have serious consequences such as stress, anxiety, irritability, social isolation and depression that may leads to lower levels of positive parent-child interactions, and less competent parenting practices (24).

Considering the vulnerability of women and the role of mothers in educating children, effort to empower them is an important element for the development of the society. Accordingly, women usually have more accurate information regarding the status of the household food security and are most affected by it. The aim of this study is to evaluate factors associated with household food insecurity and its impact on mental and physical health- of adult women who had high school aged children in Babolsar, a northern city of Iran, in 2015.

\section{Materials and Methods}

This cross-sectional study was performed on adult women who had high school aged children (aged between 14 to 17 years) in Babolsar, Mazandaran Province, in May 2015. Subjects were selected from a larger study that evaluated effect of food insecurity on adolescents psychosocial adaptive adjustment (25). A total of 300 women were invited to participate in the study that eventually 289 of them agreed to answer questions. After the description of methodology and purpose of research, a consent form was completed by participants. Data related to socio-economic characteristics, household food security, physical and mental health were collected using questionnaires through face to face interviews.

Socio-economic characteristics: The socioeconomic and demographic characteristics was determined by questionnaire designed by researchers, that included age, family size, educational level and occupational status of the subjects, educational level and occupational status of participants husbands, head of the family (male or female), insurance, support of relief organizations from family (yes, no), residential area (urban or rural) and the house ownership. Economic status of families was assessed by asking question about the number of facilities they owned at home, and then the families were categorized into two groups of economic status according to median: high and low.

Food security assessment: Household food security was assessed using USDA household food security questionnaires (26). This 18-item questionnaire was used to investigate family food security over the past 12 months. Based on the aforementioned questionnaire, households were grouped into four: secure food (scored 0-2), insecure food without hunger (scored 3-7), insecure food with average hunger (scored 8-12) and insecure food with extreme hunger (scored 13-18). The validity of the questionnaire have already been confirmed among Iranian families (6).

Short form of health survey (SF-12): SF-12, which is the short form of the SF-36 questionnaire, was used to determine mental and physical health (27). Montazeri et al. confirmed the validity of this questionnaire in Iran (28). The score of questionnaire ranges between 0 and 100, with 100 as the highest 
health level. Based on the mean score, mental and physical health status were divided into two categories (poor and good). The aforementioned questionnaire was used with the consent of the translator.

Statistical analysis method: The SPSS (version 18) was used to analyze data. To investigate the relationship between food insecurity and sociodemographic factors, the food insecurity was grouped into: food secure and food insecure. Chi-Square Tests and $t$-tests were used to investigate the significance of the relationship between independent and dependent variables. The $\mathrm{P}$-values lower than 0.05 was considered significant. Multiple Regressions was also used to investigate the correlation between food insecurity score and mental and physical health score. Ultimately, two models were prepared to adjust the effects of other variables on the relationship between the independent variable (food insecurity score) and the dependent variable (mental and physical health score). In the first model, the relationship was adjusted in terms of age, occupation and education of participants. In the second model, the variables of occupation and education of husbands, residential area (urban / rural), and family size were added to the previous variables.

\section{Results}

Household food insecurity was observed in $50.2 \%$ of the studied subjects $(30.1 \%$ food insecurity without hunger, $18 \%$ food insecurity with moderate hunger and $2.1 \%$ food insecurity with severe hunger). Participant's demographic characteristics in terms of food security status is shown in Table 1. Food insecurity showed a significant correlation with participant's age, occupation, education level of husbands and living area (urban or rural) $(\mathrm{p}<0.05)$. Furthermore, the p-value for family size was equal to 0.054 , which is almost significant suggesting that food insecurity is more prevalent in families with 4 and fewer members. Although this relationship was not statistically significant

Table 1. Characteristics of subjects based on food insecurity status

\begin{tabular}{|c|c|c|c|c|}
\hline variables $^{\mathrm{a}}$ & & food secure & food insecure & P-value \\
\hline age (Mean) & & $40.2( \pm 3.4)$ & $41.2( \pm 4.0)$ & 0.02 \\
\hline \multirow[t]{2}{*}{ Household Head (\%) } & male & $7(4.9)$ & $8(5.5)$ & 0.99 \\
\hline & female & $137(95.1)$ & $137(94.5)$ & \\
\hline \multirow[t]{3}{*}{ Education $(\%)$} & Below Diploma & $56(39.2)$ & $65(44.8)$ & 0.594 \\
\hline & Diploma & $59(41.3)$ & $56(38.6)$ & \\
\hline & College education & $28(19.6)$ & $24(16.6)$ & \\
\hline \multirow[t]{2}{*}{ Occupation } & Housekeeper & $111(77.6)$ & $118(81.4)$ & 0.52 \\
\hline & Employee & $32(22.4)$ & $27(18.6)$ & \\
\hline \multirow[t]{3}{*}{ Husbands education $(\%)$} & Below Diploma & $42(30.0)$ & $66(46.2)$ & 0.01 \\
\hline & Diploma & $44(31.4)$ & $42(29.4)$ & \\
\hline & College education & $54(38.6)$ & $35(24.5)$ & \\
\hline \multirow[t]{4}{*}{ Husbands occupation } & Unemployment or Workman & $4(2.8)$ & $8(5.5)$ & $<0.001$ \\
\hline & Self-employment & $82(56.9)$ & $107(73.8)$ & \\
\hline & Government jobs with moderate income & $31(21.5)$ & $25(17.2)$ & \\
\hline & High income (Businessman, Doctor, ...) & $27(18.8)$ & $5(3.4)$ & \\
\hline \multirow[t]{2}{*}{ Economic status } & high & $64(44.8)$ & $53(36.6)$ & 0.19 \\
\hline & low & $79(55.2)$ & $92(63.4)$ & \\
\hline \multirow[t]{2}{*}{ Residential area } & Urban & $103(71.5)$ & $123(84.8)$ & 0.01 \\
\hline & Rural & $41(28.5)$ & $22(15.2)$ & \\
\hline \multirow[t]{2}{*}{ Family size } & 4 or lower & $100(69.4)$ & $116(80.0)$ & 0.05 \\
\hline & 5 or more & $44(3.6)$ & $29(20.0)$ & \\
\hline
\end{tabular}

a quantitative variables reported as mean $( \pm \mathrm{SD})$ and qualitative variables reported as frequency $(\%)$

$\mathrm{b}$ calculated by student $\mathrm{t}$-test or chi square test 
The results on the relationship between food insecurity and mental and physical health are shown in Table 2. The mean score of the SF-12 for women in food insecure households was significantly lower than food secure households. These results suggest that food insecurity is significantly associated with lower scores of physical and mental health. The effect of food insecurity in prediction of mental and physical health score by linear regression are shown in Tables 3 and 4.

Table 3 shows the relationship between food insecurity and physical health. First, the relationship between physical health as the dependent variable and food insecurity as the independent variable investigated without entering any other variable. The results suggest a moderate prediction of physical health score by food insecurity $(p<0.001, \beta=-1.079)$. In model 1 after adjustment for age, job and education, relationship between food insecurity and physical health remained significant $(p<0.001, \beta=$ 0.974). Among covariates, only subjects age remained significant $(\mathrm{p}=0.002, \beta=0.52,95 \% \quad \mathrm{CI}=0.20-0.84)$. Moreover, in model 2 after adding participant's husbands job and education, living place and family size to former variables, the relationship between food insecurity and physical health was still significant $(\mathrm{p}<$ $0.001, \beta=-1.04)$. Also, the relationship between participants age and physical health remained significant in model $2(\mathrm{p}=0.003, \quad \beta=0.49,95 \%$ $\mathrm{CI}=0.17-0.81)$.

Table 2. Participants physical and mental health according to food insecurity

\begin{tabular}{llccc}
\hline \multicolumn{2}{c}{ variables } & food secure & food insecure & p-value $^{\mathrm{a}}$ \\
\hline Health related quality of life $^{\mathrm{b}}$ & MCS (mean \pm SD) & $48.23( \pm 10.37)$ & $43.77( \pm 11.23)$ & 0.001 \\
& PCS (mean \pm SD) & $49.73( \pm 8.77)$ & $40.91( \pm 11.11)$ & $<0.001$ \\
& & & & \\
Mental health $^{\mathrm{c}}$ & poor & $49(34.0)$ & $85(58.6)$ & $<0.001$ \\
& good & $95(66.0)$ & $60(41.4)$ & \\
Physical health $^{\mathrm{c}}$ & poor & & & \\
& good & $30(20.8)$ & $96(66.2)$ & $<0.001$ \\
\hline
\end{tabular}

a calculated by student t-test or chi square test

b Reported as mean $( \pm \mathrm{SD})$

c reported as frequency $(\%)$

Table 3. Relationship between physical health and food insecurity

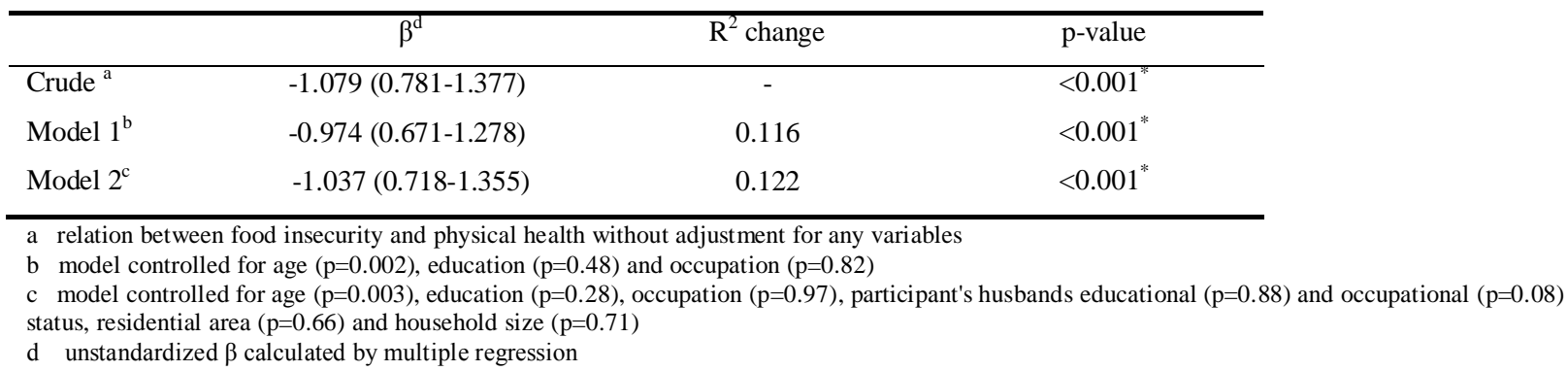

Table4. Relationship between mental health and food insecurity

\begin{tabular}{lccc}
\hline & $\beta^{\mathrm{d}}$ & $\mathrm{R}^{2}$ change & $\mathrm{p}$-value \\
\hline Crude $^{\mathrm{a}}$ & $-0.728(0.413-1.042)$ & - & $<0.001^{*}$ \\
Model 1 $^{\mathrm{b}}$ & $-0.754(0.429-1.078)$ & 0.068 & $<0.001^{*}$ \\
Model 2 $^{\mathrm{c}}$ & $-0.722(0.383-1.062)$ & 0.058 & $<0.001^{*}$ \\
\hline
\end{tabular}

a relation between food insecurity and physical health without adjustment for any variables

b model controlled for age $(\mathrm{p}=0.24)$, education $(\mathrm{p}=0.27)$ and occupation $(\mathrm{p}=0.30)$

c model controlled for age $(\mathrm{p}=0.28)$, education $(\mathrm{p}=0.10)$, occupation $(\mathrm{p}=0.37)$, participant's husbands educational $(\mathrm{p}=0.26)$ and occupational $(\mathrm{p}=0.42)$ status, residential area $(\mathrm{p}=0.10)$ and household size $(\mathrm{p}=0.47)$

$\mathrm{d}$ unstandardized $\beta$ calculated by multiple regression 
Association between food insecurity and mental health is shown in table 4 . Without adjustment for any covariate, food insecurity had a reverse effect on mental health score $(p=0.001, \beta=-0.728)$. After adjustment for age, job and education in model 1 , relationship between food insecurity and mental health was still significant $(p=0.001, \beta=-0.754)$. In model 2, participant's husbands job and education, living place and household size was also entered in addition to the model 1 variables. It was found that the highest food insecurity is related to lowest mental health after adjustment for variables existed in model 2. There was no significant relationship between mental health and covariates that entered in the regression models.

\section{Disc ussion}

This research aimed to investigate factors associated with households' food insecurity and its association with mental and physical health of mothers with high school children in Babolsar city. More than half of the study population were food insecure. Food insecurity had a significant relationship with participant's age, living area and husband's job and education level. Based on the findings, food insecurity is related to poor physical and mental health. Investigating the relationship between food insecurity and mental and physical health showed that even after adjustment for confounders, food insecurity is significantly associated with lower score of mental and physical health.

The present study suggests that mental health can be negatively affected in food insecure households. Two other studies in different districts of Tehran showed a similar association between food insecurity and depression $(29,30)$. The results of the present study were consistent with other studies around the world $(31,32)$. In a study conducted among 676 African-American and white women, the relationship between household food insufficiency and poor mental health was reported (33). Poor or inadequate diet quality due to food insecurity can eventually lead to psychological stress (34). The association between lack of enough food and decline in diet quality has been shown in previous studies $(35,36)$. However, due to the cross-sectional nature of the present study, establishing a causal relationship is impossible and this is probable that the decrease in mental health causes lower income and which leads to further food insecurity (37).

Another result from this study was poor physical health status associated with a rise in food insecurity. Other studies showed this relationship around the world $(38,39)$. This result can be due to food insecurity impact on poor nutritional status that can have an adverse effect on physical function. Moreover food insecurity can exacerbate the effects of other diseases on health (40). As described in the previous paragraph, food insecurity can also be affected by physical health status and it has been showed that poor physical health resulted in less intention to work and lower income (41).

Based on findings of this study, prevalence of food insecurity in women's household with high school children was $50.2 \%$. In the study of Mohammadzadeh et al, in a similar population, prevalence of food insecurity was reported $36.6 \%$ (18). Safarpur et al. reported $51 \%$ of food insecurity in Bandar Anzali, Iran (42). Payab et al. reported $50.2 \%$ of food insecurity prevalence which is in accordance with the findings of the present study (29).

Results of this study, is in line with Payab and colleagues (29), they have showed that food insecurity is directly associated with women's age. However, there are some studies that did not approve such a relationship $(18,32,43)$. In this study, older women may have more children and more member of household causes more need to foods, and it could be the reason for developing food insecurity state (44).

In addition, the present study suggests that food insecurity status is inversely related to participant's husbands job and education level. Dastgiri in a study conducted in a region of Tabriz city reported similar result (4). Moreover, Payab et al. stated that food insecurity was inversely associated with education and occupational status of head of households (29). Furthermore, a study in Brazil reported that Parents' lack of university education was significantly associated with household food insecurity (45). Usfar survey among urban and rural households in Indonesia has confirmed this relationship (46). As we know, higher education leads to better job and more income, so households could spend more for food that lowers food insecurity status (47). 
There are several studies regarding the association between food insecurity and different aspects of health, but there is more need to conduct well designed studies to be precisely ensured how food insecurity can affect the health status. It should also be noted that both food insecurity and human health could be affected by geographical area and culture (48, 49); therefore, this issue should be studied separately in different regions and countries. The limitation of this study was that using questionnaire relies on participant's memory and also their perception about situation (food security or health status), so its accuracy is uncertain. Moreover, according to the cross-sectional nature of the study, causal relationship is not clear. A few studies have examined food insecurity and its consequences in northern Iran, and this could be the strength of this study that we have new information about food insecurity in this region and policy-makers can use it in their planning.

Finally, food insecurity can be considered as an independent risk factor for poor mental and physical health in women. This study shows that women as a vulnerable member of family, may be more affected by food insecurity that can results in poor mental and physical health of them. This relationship was independent of participant's age, education, occupation, their husbands educational and occupational status, residential area and family size. Considering the role of women in raising children and keeping families together, identifying factors affecting their health could be improving community problems.

\section{Acknowledgement}

The authors thank all participants, teachers and school administrators for their cooperating with this study.

\section{Financial disclosure}

None of the authors had any conflicts of interest to disclose.

\section{Funding/Support}

This study was part of a MSc thesis supported by Tehran University of Medical Science (grant No: 9401-161-28665).

\section{References}

1. Fao WF. IFAD (2012) The state of food insecurity in the world 2012. Economic Growth is necessary but not Sufficient to Accelerate Reduction of Hunger and Malnutrition. FAO, Rome, Italy.:1-61.

2. Kendall A, Olson CM, Frongillo Jr EA. Validation of the Radimer/Cornell measures of hunger and food insecurity. The Journal of nutrition. 1995;125(11):2793.

3. Frongillo EA, Nanama S. Development and validation of an experience-based measure of household food insecurity within and across seasons in northern Burkina Faso. The Journal of Nutrition. 2006;136(5):1409S-19S.

4. Dastgiri S, Mahdavi R, TuTunchi H, Faramarzi E. Prevalence of obesity, food choices and socio-economic status: a cross-sectional study in the north-west of Iran. Public health nutrition. 2006;9(08):996-1000.

5. Sarlio-Lähteenkorva S, Lahelma E. Food insecurity is associated with past and present economic disadvantage and body mass index. The Journal of nutrition. 2001;131(11):2880-4.

6. Ramesh T. The Prevalence of food insecurity and some associated factors among Shirazian households in 2009 [dissertation] Tehran: Shahid Beheshti University. MC; 2009.

7. Casey PH, Simpson PM, Gossett JM, Bogle ML, Champagne CM, Connell $\mathrm{C}$, et al. The association of child and household food insecurity with childhood overweight status. Pediatrics. 2006;118(5):e1406-e13.

8. Gervais J, Ledrou I. Food insecurity. Health Reports. $2005 ; 16(3): 47$

9. Hamilton WL, Cook JT. Household food security in the United States in 1995: technical report of the food security measurement project. 1997.

10. Lorenzana PA, Sanjur D. Abbreviated measures of food sufficiency validly estimate the food security level of poor households: measuring household food security. The Journal of nutrition. 1999;129(3):687-92.

11. Rose D. Economic determinants and dietary consequences of food insecurity in the United States. The Journal of nutrition. 1999;129(2):517S-20S.

12. Rose D, Gundersen C, Oliveira V. Socio-Economic Determinants of Food Insecurity in the United States. United States Department of Agriculture, Economic Research Service; 1998.

13. Carter P, Taylor A. Food insecurity in South Australia. Public Health Bulletin SA. 2007;4(1):23-5.

14. Turrell G. Structural, material and economic influences on the food-purchasing choices of socioeconomic groups. Australian and New Zealand Journal of Public Health. 1996;20(6):611-7. 
15. Turrell G, Hewitt B, Patterson C, Oldenburg B, Gould T. Socioeconomic differences in food purchasing behaviour and suggested implications for diet-related health promotion. Journal of Human Nutrition and Dietetics. 2002;15(5):355-64.

16. Laraia BA, Siega-Riz AM, Gundersen C, Dole N. Psychosocial factors and socioeconomic indicators are associated with household food insecurity among pregnant women. The Journal of nutrition. 2006;136(1):177-82.

17. Drewnowski A, Specter S. Poverty and obesity: the role of energy density and energy costs. The American journal of clinical nutrition. 2004;79(1):6-16.

18. Mohammadzadeh A, Dorosty A, Eshraghian M. Household Food Security Status and Food Consumption among High School Students in Esfahan, Iran. Iranian Journal of Epidemiology. 2011;7(1):38-43.

19. Patel V. Mental health in low-and middle-income countries. British Medical Bulletin. 2007.

20. Kaltiala-Heino R, Ranta K, Fröjd S. [Adolescent mental health promotion in school context]. Duodecim; laaketieteellinen aikakauskirja. 2009;126(17):2033-9.

21. Kursmark M, Weitzman M. Recent findings concerning childhood food insecurity. Current Opinion in Clinical Nutrition \& Metabolic Care. 2009;12(3):310-6.

22. Ivers LC, Cullen KA. Food insecurity: special considerations for women. The American journal of clinical nutrition. 2011;94(6):1740S-4S.

23. Matheson J, McIntyre L. Women respondents report higher household food insecurity than do men in similar Canadian households. Public health nutrition. 2014;17(01):40-8.

24. Collins L. The impact of food insecurity on women's mental health: how it negatively affects children's health and development. Journal of the Motherhood Initiative for Research and Community Involvement. 2009;11(1).

25. Ramezani Ahmadi A, Vedadhir A, Heshmat R, Pouraram H. The Relationship between Food Insecurity and Adjustment of High School Students: Case-Control Study. Iranian Journal of Nutrition Sciences \& Food Technology. 2016;11(3):43-52.

26. Pinstrup-Andersen P. Food security: definition and measurement. Food security. 2009;1(1):5-7.

27. Ware JE, Kosinski M, Keller SD. SF-12: How to score the SF-12 physical and mental health summary scales: Health Institute, New England Medical Center; 1995.

28. Montazeri A, Vahdaninia M, Mousavi SJ, Omidvari S. The Iranian version of 12-item Short Form Health Survey (SF-12): factor structure, internal consistency and construct validity. BMC public health. 2009;9(1):1.

29. Payab M, Dorosty A, Eshraghian M, Rostami R, Siassi F. The association of family food security and depression in mothers having primary school children in Ray-Iran. J Diabetes Metab Disord. 2014;13(1):65.

30. Mirzadehahari Z, Mohammadi-Nasrabadi F, Eini-Zinab H, Khosravi M, Mousavi N, Agasi M. Survey of association between major depression disorder in women and household food insecurity. Iranian Journal of Nutrition Sciences \& Food Technology. 2015;10(1):9-20.

31. Carter KN, Kruse K, Blakely T, Collings S. The association of food security with psychological distress in New Zealand and any gender differences. Social Science \& Medicine. 2011;72(9):1463-71.

32. Huddleston-Casas C, Charnigo R, Simmons LA. Food insecurity and maternal depression in rural, low-income families: a longitudinal investigation. Public health nutrition. 2009;12(08):1133-40.

33. Siefert K, Heflin CM, Corcoran ME, Williams DR. Food insufficiency and physical and mental health in a longitudinal survey of welfare recipients. Journal of health and social behavior. 2004;45(2):171-86.

34. Hadley C, Stevenson EGJ, Tadesse Y, Belachew T. Rapidly rising food prices and the experience of food insecurity in urban Ethiopia: impacts on health and well-being. Social Science \& Medicine. 2012;75(12):2412-9.

35. Heflin CM, Siefert K, Williams DR. Food insufficiency and women's mental health: Findings from a 3-year panel of welfare recipients. Social Science \& Medicine. 2005;61(9):1971-82.

36. Lachance L, Sean Martin M, Kaduri P, Godoy-Paiz P, Ginieniewicz J, Tarasuk V, et al. Food insecurity, diet quality, and mental health in culturally diverse adolescents. Ethnicity and Inequalities in Health and Social Care. 2014;7(1):14-22.

37. Garg A, Toy S, Tripodis Y, Cook J, Cordella N. Influence of Maternal Depression on Household Food Insecurity for Low-Income Families. Academic Pediatrics. 2015;15(3):305-10.

38. Siefert K, Heflin CM, Corcoran ME, Williams DR. Food insufficiency and the physical and mental health of low-income women. Women \& health. 2001;32(12):159-77.

39. Stuff JE, Casey PH, Szeto KL, Gossett JM, Robbins JM, Simpson PM, et al. Household food insecurity is associated with adult health status. The Journal of nutrition. 2004; 134(9):2330-5.

40. Weiser SD, Tsai AC, Gupta R, Frongillo EA, Kawuma A, Senkungu J, et al. Food insecurity is associated with morbidity and patterns of healthcare utilization among HIV-infected individuals in a resource-poor setting. AIDS (London, England). 2012;26(1):67.

41. Anderson PM, Butcher KF, Hoynes HW, Schanzenbach DW. Beyond Income: What Else Predicts Very Low Food Security among Children? 2014. 
42. Safarpour M, Dorosty A, Hosseini SM, Noshari FR, Safarpour M, Maskooni MD, et al. The prevalence and consequences of food insecurity and its association with socio-economic factors (persian). Knowledge And Health. 2013;8(4):193-8.

43. Kaiser LL, Townsend MS, Melgar-Quiñonez HR, Fujii ML, Crawford PB. Choice of instrument influences relations between food insecurity and obesity in Latino women. The American journal of clinical nutrition. 2004;80(5):1372-8.

44. Uzma I, Muhammad SB. Determinants of household food security: An empirical analysis for Pakistan. International Journal of Social Economics. 2004;31(8):753-66.

45. Panigassi G, Segall-Corrêa AM, Marin-León L, PérezEscamilla R, Sampaio MdFA, Maranha LK. Food insecurity as an indicator of inequity: analysis of a population survey. Cadernos de Saude Publica. 2008;24(10):2376-84.
46. Usfar AA, Fahmida U, Februhartanty J. Household food security status measured by the US-Household Food Security/Hunger Survey Module (US-FSSM) is in line with coping strategy indicators found in urban and rural Indonesia. Asia Pacific journal of clinical nutrition. 2007;16(2):368.

47. Hannum E, Liu J, Frongillo EA. Poverty, food insecurity and nutritional deprivation in rural China: Implications for children's literacy achievement. International Journal of Educational Development. 2014;34:90-7.

48. Shaw SJ, Huebner C, Armin J, Orzech K, Vivian J. The role of culture in health literacy and chronic disease screening and management. Journal of Immigrant and Minority Health. 2009;11(6):460-7.

49. Gregory PJ, Ingram JS, Brklacich M. Climate change and food security. Philosophical Transactions of the Royal Society B: Biological Sciences. 2005;360(1463):2139-48. 